\title{
Rancang Bangun Sistem Informasi Kepegawaian Berbasis Web Pada CV Citra Pratama Global
}

\author{
Design and Development of Web Based Staffing Information System \\ at CV Citra Pratama Global
}

\author{
Stefany Wijaya ${ }^{1}$, Putut Ali Nurdin ${ }^{2}$, Desi Pibriana ${ }^{3}$ \\ ${ }^{1,2,3}$ Program Studi Sistem Informasi, STMIK Global Informatika MDP \\ E-mail: ${ }^{1}$ stefanywijaya97@mhs.mdp.ac.id, ${ }^{2}$ pututali@mhs.mdp.ac.id, ${ }^{3}$ desi.pibriana@mdp.ac.id
}

\begin{abstract}
Abstrak
CV. Citra Pratama Global adalah perusahaan yang bergerak pada bidang kontraktor, supplier ATK di perkantoran, dan pengadaan komputer. Dalam pengelolaan kepegawaian CV Citra Pratama Global memiliki beberapa kendala diantaranya HRD membutuhkan waktu yang lama dalam menyeleksi berkas karyawan karena tidak adanya record data calon karyawan, rekapitulasi absen karyawan masih manual mengakibatkan terjadinya manipulasi jam kerja, data cuti dan izin sulit dimonitoring sehingga terjadi kekeliruan dalam perhitungan sisa jatah cuti dan izin mengakibatkan karyawan yang sudah habis masa cuti dan izin bisa mengambil kembali, perekapan mutasi, demosi, promosi dan surat peringatan masih menggunakan form yang diarsipkan pada berkas karyawan sehingga pimpinan lambat dalam menerima laporan dan penilaian kerja karyawan membutuhkan waktu lama karena menggunakan catatan kerja yang dibuat oleh supervisor. Oleh karena itu, dirancanglah suatu Sistem Informasi Kepegawaian yang berbasis website dengan bahasa pemrograman PHP dan MySQL sebagai penyimpanan data. Perancangan sistem informasi ini dilakukan dengan menggunakan metodologi iterasi. Hasil dari perancangan ini adalah sebuah rancangan sistem informasi yang dapat membantu CV Citra Pratama Global dalam pengelolaan kepegawaian yang cepat, tepat dan akurat.
\end{abstract}

Kata kunci: Sistem Informasi Kepegawaian, Iterasi, PHP, dan MySQL

\begin{abstract}
CV. Citra Pratama Global is a company engaged in the field of contractors, office stationery suppliers, and computer procurement. In managing staff, Citra Citra Pratama Global has several obstacles, including HRD which requires a long time in selecting employee files due to the absence of prospective employee data records, employee recapitulation absent is still manual resulting in manipulation of working hours, leave data and permits are difficult to monitor so that errors occur in the calculation of the remaining leave and permit ratios resulting in employees who have expired leave and permit can take back, recording mutation, demotion, promotion and warning letters still use forms that are archived in employee files so that leaders are slow in receiving reports and assessments of employee work takes a long time because it uses work records created by supervisors. Therefore, a website-based Personnel Information System was designed with PHP and MySQL programming languages as data storage. The design of this information system is carried out using an iteration methodology. The result of this design is an information system design that can help CV Citra Pratama Global in managing staff that is fast, precise and accurate.
\end{abstract}

Keywords: Personnel Information System, Iteration, PHP, and MySQL 


\section{PENDAHULUAN}

Teknologi informasi dan komputer pada saat ini berkembang sangat cepat dikalangan masyarakat, kebutuhan akan informasi tersebut semakin meningkat baik dikalangan masyarakat awam atau intelektual. Hal ini berkaitan dengan kegiatan-kegiatan yang sering dilakukan manusia yang biasanya dilakukan secara manual dan tradisional, kini akan semakin lebih cepat dan tepat jika dilakukan dengan bantuan mesin yaitu teknologi komputer.

Selama ini, dalam pengelolaan kepegawaian CV Citra Pratama Global masih mengalami beberapa kendala diantaranya HRD membutuhkan waktu yang lama dalam menyeleksi berkas karyawan karena tidak adanya record data calon karyawan, rekapitulasi absen karyawan masih manual mengakibatkan terjadinya manipulasi jam kerja, data cuti dan izin sulit dimonitoring sehingga terjadi kekeliruan dalam perhitungan sisa jatah cuti dan izin mengakibatkan karyawan yang sudah habis masa cuti dan izin bisa mengambil kembali, perekapan mutasi, demosi, promosi dan surat peringatan masih menggunakan form yang diarsipkan pada berkas karyawan sehingga pimpinan lambat dalam menerima laporan dan penilaian kerja karyawan membutuhkan waktu lama karena menggunakan catatan kerja yang dibuat oleh supervisor. Oleh karena itu akan dirancang suatu sistem informasi kepegawaian untuk menggantikan sistem yang lama agar seluruh proses kepegawaian yang ada di CV Citra Pratama Global dapat dilakukan dengan mudah, cepat dan akurat.

Menurut penelitian terdahulu, sistem informasi kepegawaian merupakan sebuah sistem informasi manajemen yang berfungsi untuk menyediakan berupa akses data-data dan informasiinformasi, mengumpulkan data-data, serta mengelola data sebagai pendukung dalam proses pengambilan keputusan yang bertujuan untuk meningkatkan kinerja perusahaan terutama dalam bidang kepegawaian [1]. Sistem informasi kepegawaian mempunyai peranan penting dalam menyiapkan sumber daya manusia secara efektif dan efisien melalui tersedianya informasi sumber daya manusia yang cepat, lengkap, dan akurat [2]. Penelitian serupa pernah dilakukan oleh [3] untuk membuat sistem informasi kepegawaian yang membahas mengenai pendataan karyawan, pengontrolan jatah cuti, lembur, absensi dan penggajian karyawan. Penelitian lain dilakukan oleh [4] membuat sistem informasi kepegawaian yang terdiri dari data bagian, jabatan, pegawai kependidikan, pegawai pendidik, pengisian penilaian kependidikan, pengisian nilai pendidik dan rekap absensi, hasil dari penelitian tersebut mempermudah pegawai dalam mengupdate informasi data pegawai dan memudahkan dalam mengontrol kinerja pegawai. Sistem informasi kepegawaian dapat meliputi pendataan pegawai, pengolahan data informasi terkait pegawai untuk menghasilkan informasi yang cepat, lengkap, dan akurat dalam rangka mendukung administrasi kepegawaian.

\section{a. Metode Penelitian}

\section{METODE PENELITIAN}

Adapun tahap-tahap dalam pengumpulan data sebagai berikut:

\section{Observasi}

Pada tahap ini penulis melakukan pengamatan langsung sistem yang berjalan pada perusahaan.

2. Wawancara

Pada tahap ini penulis melakukan wawancara untuk pengumpulan informasi mengenai data-data yang berkaitan dengan penelitian.

3. Studi Pustaka

Pada tahap ini penulis mencari sumber referensi seperti buku-buku maupun jurnal yang berkaitan dengan penelitian.

\section{b. Metodologi Pengembangan Sistem}

Metodologi penelitian yang digunakan penulis dalam membuat sistem ini yaitu metodologi iterasi (iterative model). Metodologi iterative adalah suatu model pengembangan 
sistem yang mengkombinasikan proses-proses pada model air terjun dan iterative model prototype [5]. Adapun beberapa tahapan dalam metode iterasi ini diantaranya:

1.Tahap Perencanaan

Pada tahap ini yang dilakukan adalah menentukan latar belakang, ruang lingkup dan metodologi yang digunakan.

2.Tahap Analisis

Pada tahap ini yang dilakukan adalah menganalisis sistem kepegawaian yang telah berjalan dan menganalisis permasalahan yang terjadi pada perusahaan.

3.Tahap Perancangan

Dari analisis permasalahan yang ada, dilakukan perancangan sistem yang baru sesuai kebutuhan perusahaan.

4.Tahap Implementasi

Pada tahap ini dibuat sistem aplikasi dan database menggunakan $P H P$ dan $M y S Q L$. 5.Tahap Pemeliharaan

Tahap ini mencakup seluruh proses yang diperlukan untuk menjamin kelangsungan, kelancaran, dan penyimpanan sistem yang baru serta mencegah kehilangan sistem yang baru.

\section{HASIL DAN PEMBAHASAN}

\subsection{Analisis Permasalahan}

Dalam menganalisis permasalahan penulis menggunakan analisis PIECES. Dari analisis ini biasanya didapatkan beberapa masalah utama. Hal ini penting karena biasanya yang muncul di permukaan bukan masalah utama, tetapi hanya gejala dari masalah utama saja[6].

\section{Performance}

Lamanya waktu yang diperlukan pada proses perekapan data absen lapangan dan penilaian karyawan dikarenakan selama ini absen masih manual menggunakan kertas absensi.

Lamanya proses pencarian data karyawan baru dikarenakan HRD harus mencari satu persatu berkas lamaran dan harus meng input data karyawan baru ke dalam komputer.

2. Information

Informasi surat peringatan yang di dapat karyawan sulit dimonitoring oleh HRD dan pimpinan, dikarenakan masih diarsipkan pada berkas karyawan tersebut.

Tidak akuratnya perhitungan absensi jam kerja yang di input karyawan lapangan, sehingga terjadi selisih pada saat proses perekapan.

Tidak akuratnya perhitungan cuti menurut karyawan dengan perhitungan HRD sehingga perusahaan tetap memberikan cuti kepada pegawai tersebut, meski jatah cutinya telah habis.

\section{Economic}

Perusahaan juga akan merugi jika membayar gaji karyawan yang tidak sesuai dengan jam kerja yang ada dilapangan, dikarenakan selisih dalam perhitungan absensi.

Karyawan akan merugi apabila gaji yang diterima tidak sesuai, dikarenakan selisih dalam perhitungan pada saat proses perekapan absen.

4. Control

Rentan terjadi manipulasi jam kerja karena absen masih menggunakan kertas rekapan absen dan tidak adanya keamanan pada sistem absensi saat ini .

Tidak terkontrolnya sisa jatah cuti karyawan sehingga mengakibatkan karyawan yang jatah cutinya telah habis masih bisa cuti kembali.

Tidak terkontrolnya berkas mutasi, demosi, dan promosi mengakibatkan lambatnya laporan kepada bagian keuangan sehingga akan berpengaruh pada gaji karyawan.

5. Efficiency

Beban kerja yang ditimbulkan lebih banyak karena proses pencatatan, rekapitulasi dan pencarian absensi sehingga HRD harus berulang-ulang untuk pengecekan pekerjaan tersebut 


\section{Service}

Layanan pengajuan cuti dan izin pegawai cenderung sulit karena pegawai harus datang kekantor untuk mengambil form cuti dan izin.

\subsection{Analisis Kebutuhan}

Kebutuhan yang harus dipenuhi oleh perangkat lunak terdiri dari dua macam yakni kebutuhan fungsional dan non fungsional.

\subsubsection{Kebutuhan Fungsional}

Kebutuhan fungsional adalah jenis kebutuhan yang berisi proses-proses apa saja yang nantinya dilakukan oleh system [6]. Kebutuhan fungsional yang harus dipenuhi oleh sistem berdasarkan analisis masalah yang telah diuraikan meliputi:

1. Sistem dapat membagi hak akses masing-masing user.

2. Sistem dapat membantu HRD dalam proses rekrutmen karyawan baru sehingga dalam menyeleksi berkas calon karyawan baru menjadi lebih cepat.

3. Sistem dapat membuat perhitungan cuti sehingga karyawan yang telah habis masa cutinya tidak dapat mengambil cuti kembali.

4. Sistem dapat mempermudah karyawan dalam mengajukan cuti dan izin.

5. Sistem dapat membantu perekapan absen dan perekapan karyawan baru sehingga dapat mempercepat dalam pencarian rekapitulasi absen dan data karyawan baru.

6. Sistem dapat membantu supervisor dalam melakukan penilaian kerja sehingga laporan yang menjadi lebih akurat dan cepat.

7. Sistem dapat membantu pimpinan dalam memonitoring surat peringatan yang didapat karyawan.

8. Sistem dapat membantu proses demosi, mutasi dan promosi karyawan.

\subsubsection{Kebutuhan Non Fungsional}

Kebutuhan non fungsional adalah tipe kebutuhan yang berisi properti perilaku yang dimiliki oleh sistem[6]. Kebutuhan nonfungsional yang telah diuraikan kemudian dirangkum dalam Tabel 1 dengan klasifikasi PIECES framework.

Tabel 1. Kebutuhan Non Fungsional

\begin{tabular}{|c|c|}
\hline Performance & $\begin{array}{l}\text { - Diharapkan dapat membantu dalam proses perekapan } \\
\text { absensi dan proses penilaian kinerja karyawan } \\
\text { sehingga dapat mempercepat proses evaluasi kinerja } \\
\text { karyawan } \\
\text { - Diharapkan dapat mempermudah dalam proses } \\
\text { pencarian data karyawan baru. }\end{array}$ \\
\hline Information & $\begin{array}{l}\text { - Data yang berhubungan dengan informasi laporan } \\
\text { karyawan dan laporan cuti serta izin menjadi lebih } \\
\text { update } \\
\text { - Diharapkan dapat memberikan informasi tentang surat } \\
\text { peringatan karyawan agar dapat dimonitoring oleh } \\
\text { HRD } \\
\text { - Dapat memberikan informasi yang lebih akurat } \\
\text { terhadap proses rekapitulasi absensi dan informasi } \\
\text { perhitungan cuti karyawan }\end{array}$ \\
\hline Economic & $\begin{array}{l}\text { - Diharapkan sistem dapat meminimalisir kerugian } \\
\text { perusahaan dikarenakan kurang updatenya informasi } \\
\text { tentang perubahan gaji serta laporan demosi, promosi. }\end{array}$ \\
\hline Control & $\begin{array}{l}\text { Diharapkan sistem dapat mengkontrol absensi } \\
\text { pegawai sehingga tidak ada manipulasi jam kerja dan }\end{array}$ \\
\hline
\end{tabular}




\begin{tabular}{|l|l|}
\hline & $\begin{array}{l}\text { rekapitulasi data pegawai dapat terkontrol secara } \\
\text { berkala oleh HRD } \\
\text { - }\end{array}$ \\
& $\begin{array}{l}\text { Pengendalian terhadap sisa jatah cuti dan izin } \\
\text { karyawan sehingga perhitungan menjadi lebih akurat }\end{array}$ \\
\hline Efficiency & $\begin{array}{l}\text { Dapat mengurangi beban kerja pada saat proses } \\
\text { seleksi berkas karyawan baru sehingga nantinya } \\
\text { perusahaan lebih cepat dalam mencari dokumentasi } \\
\text { penerimaan karyawan baru pencatatan, pencarian serta } \\
\text { rekapitulasi absensi secara berkala }\end{array}$ \\
\hline Service & $\begin{array}{l}\text { Diharapkan dapat mempermudah karyawan dalam } \\
\text { proses pengajuan cuti dan izin } \\
\text { Sistem dapat memberikan data-data karyawan yang } \\
\text { lengkap dan akurat, sehingga dapat membantu } \\
\text { perusahaan terhadap pemberian gaji yang rentan } \\
\text { tertunda dikarenakan laporan mutasi, demosi, dan } \\
\text { promosi }\end{array}$ \\
\hline
\end{tabular}

\subsection{Rancangan Sistem}

\subsubsection{Diagram Konteks}

Diagram konteks adalah diagram tingkat atas, yaitu diagram secara global dari sebuah sistem informasi yang menggambarkan aliran-aliran data ke dalam dan ke luar dari dalam dan luar entitas eksternal[7]. Adapun diagram konteks CV Citra Pratama Global dapat dilihat pada Gambar 1.

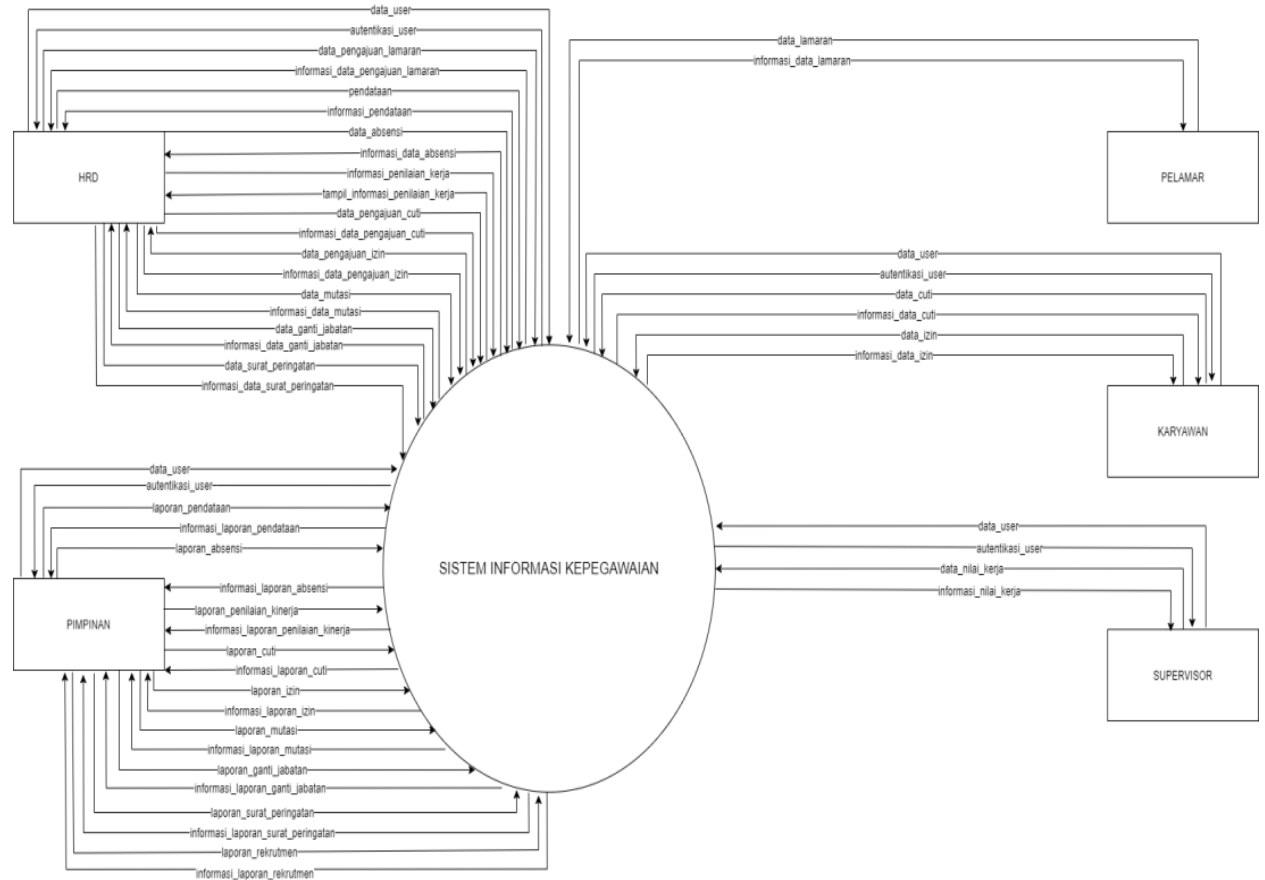

Gambar 1. Diagram Konteks

\subsubsection{Entity Relationship Diagram}

Entity Relationship Diagram (ERD) digunakan untuk menjelaskan hubungan antar data dalam basis data kepada pengguna secara logis[8]. Model ERD digunakan untuk menggambarkan hubungan antar entitas didalam suatu sistem, akan tetapi ERD tidak menggambarkan proses dan aliran data pada sistem. Adapun entity relationship diagram dapat dilihat pada Gambar 2. 


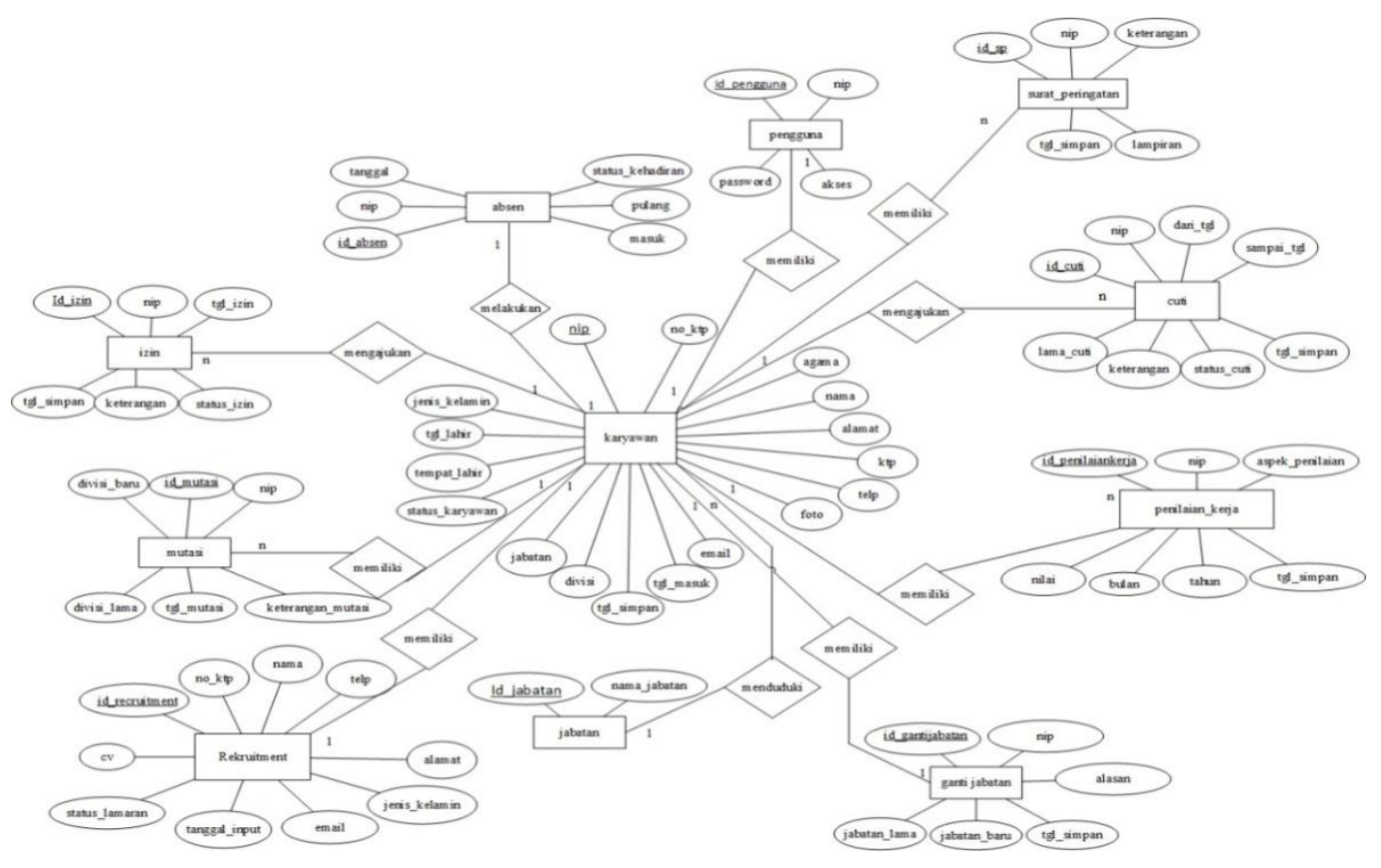

Gambar 2. Entity Relationship Diagram

\subsubsection{Data Flow Diagram (DFD)}

DFD adalah penganalisis sistem dapat merepresentasi proses-proses data di dalam organisasi. Pendekatan aliran data menekankan logika yang mendasari sistem. Dengan menggunakan kombinasi dari empat simbol, penganalisis sistem dapat menciptakan suatu gambaran proses-proses yang bisa menampilkan dokumentasi sistem yang solid [9]. DFD adalah suatu proses penggambaran grafik aliran informasi yang diaplikasikan sebagai data yang mengalir dari (input) dan keluaran (output) [10]. Data Flow Diagram level nol logis merupakan gambaran dekomposisi yang diambil dari diagram konteks. DFD ini menunjukkan proses yang menyusun sistem yang mempunyai aliran data masuk dan aliran data keluar dari simpanan data. Adapun DFD level nol dapat dilihat pada Gambar 3. 
JTSI, Vol. 1, No. 2, September 2020: 168-179

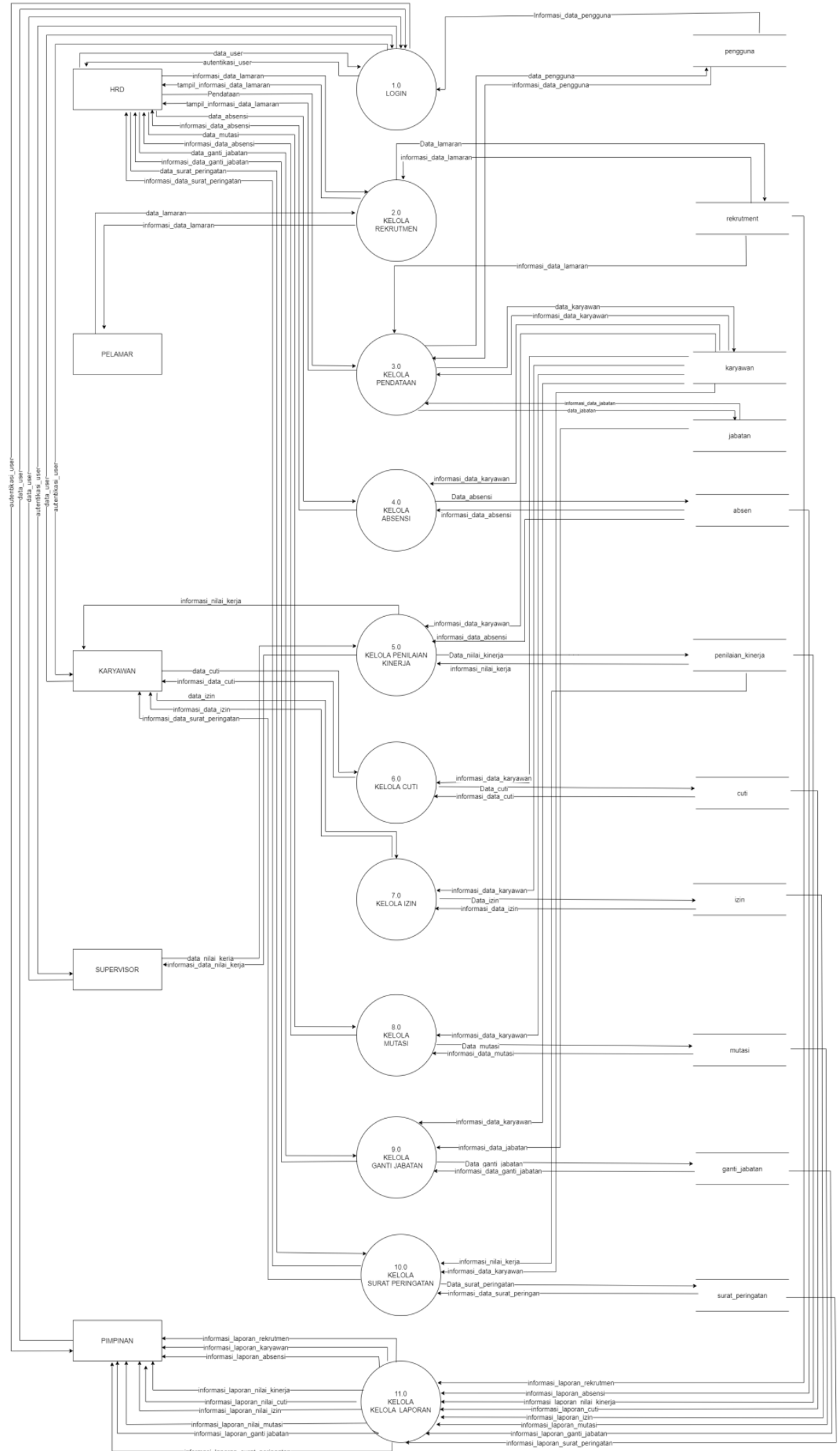

Gambar 3. Data Flow Diagram Level Nol Logis

\subsection{Rancangan Antarmuka Sistem yang Diusulkan}

\subsubsection{Rancangan Antarmuka Beranda Pimpinan}


Rancangan antar muka beranda pimpinan adalah halaman utama yang menunjukkan hak akses pimpinan, dimana pimpinan berhak mengakses laporan karyawan, laporan cuti, laporan izin, laporan sp, laporan penilaian kerja, laporan rekruitment, laporan absensi, laporan mutasi dan laporan ganti jabatan. Adapun rancangan antarmuka berandapimpinan dapat dilihat pada Gambar 4.

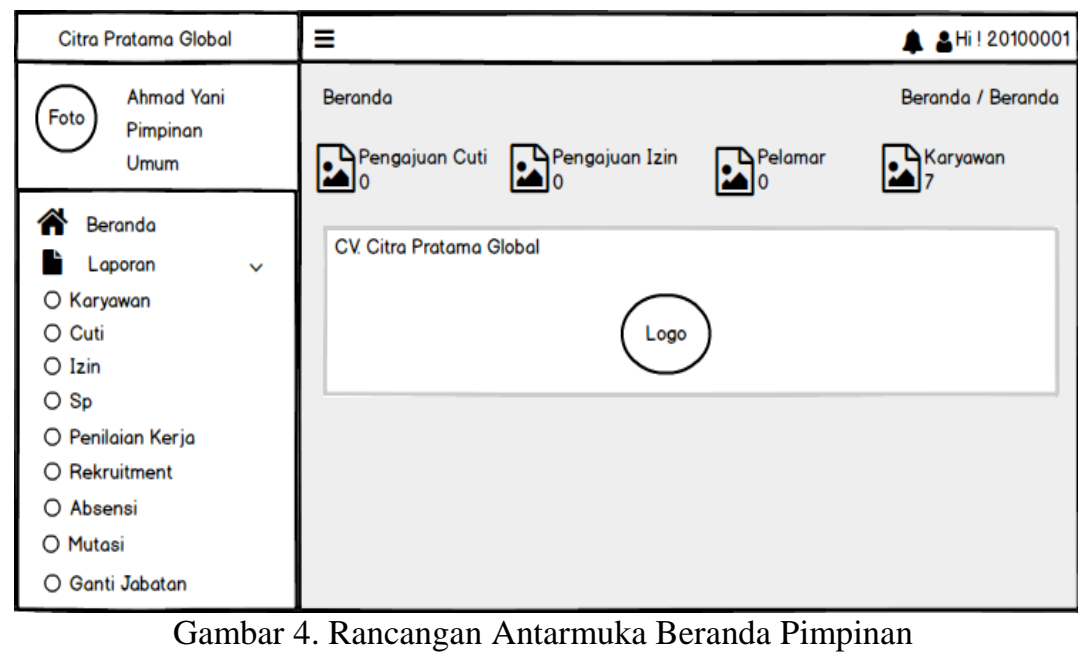

\subsubsection{Rancangan Antarmuka Beranda HRD}

Rancangan antar muka beranda $H R D$ adalah halaman utama yang menunjukkan hak akses $H R D$, dimana $H R D$ berhak mengakses kelola rekrutment, karyawan, pengguna, mutasi, ganti jabatan, cuti, izin, sp karyawan dan absensi. Adapun rancangan antarmuka beranda $H R D$ dapat dilihat pada Gambar 5.

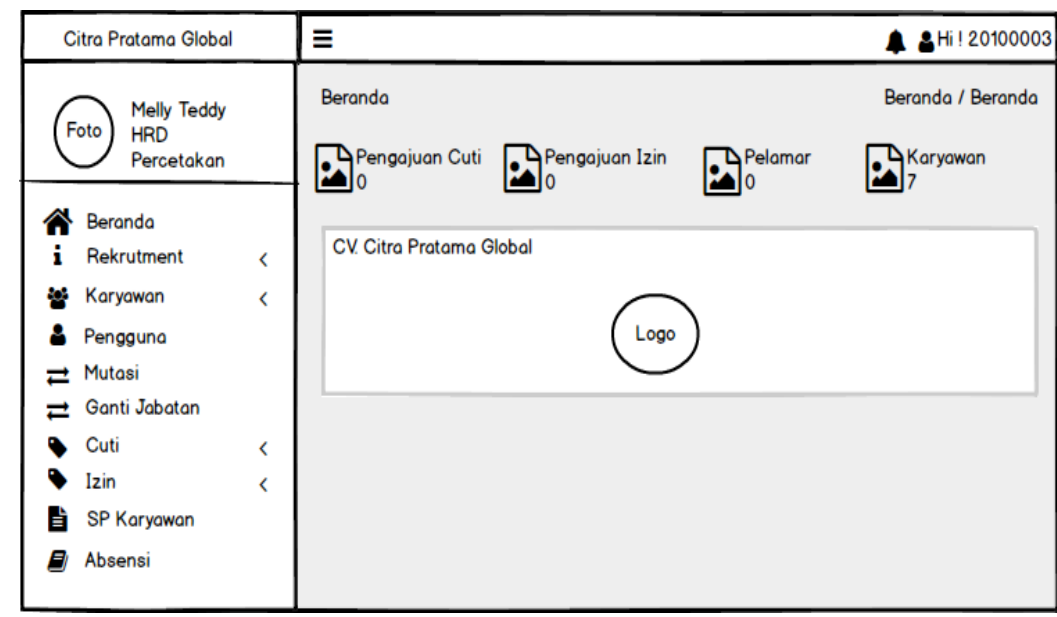

Gambar 5. Rancangan Antarmuka Beranda HRD

\subsubsection{Rancangan Antarmuka Beranda Supervisor}

Rancangan antarmuka beranda supervisor adalah halaman utama yang menunjukkan hak akses supervisor, dimana supervisor berhak mengakses kelola penilaian kerja, pengajuan cuti, pengajuan izin, info sp, info absensi, penggantian jabatan dan info mutasi. Adapun rancangan antarmuka beranda supervisor dapat dilihat pada Gambar 6. 
JTSI, Vol. 1, No. 2, September 2020: 168-179

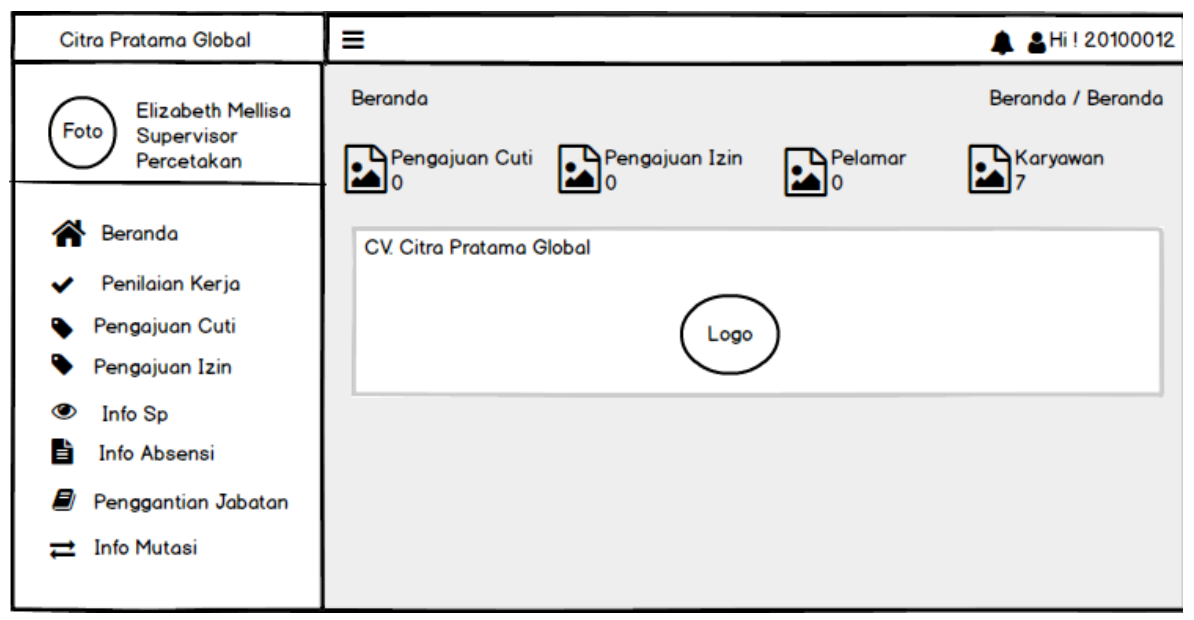

Gambar 6. Rancangan Antarmuka Beranda Supervisor

\subsubsection{Rancangan Antarmuka Beranda Karyawan}

Rancangan antarmuka beranda karyawan adalah halaman utama yang menunjukkan hak akses karyawan, dimana karyawan berhak pengajuan cuti, pengajuan izin, info sp, info absensi, penggantian jabatan dan info mutasi. Adapun rancangan antarmuka beranda karyawan dapat dilihat pada Gambar 7.

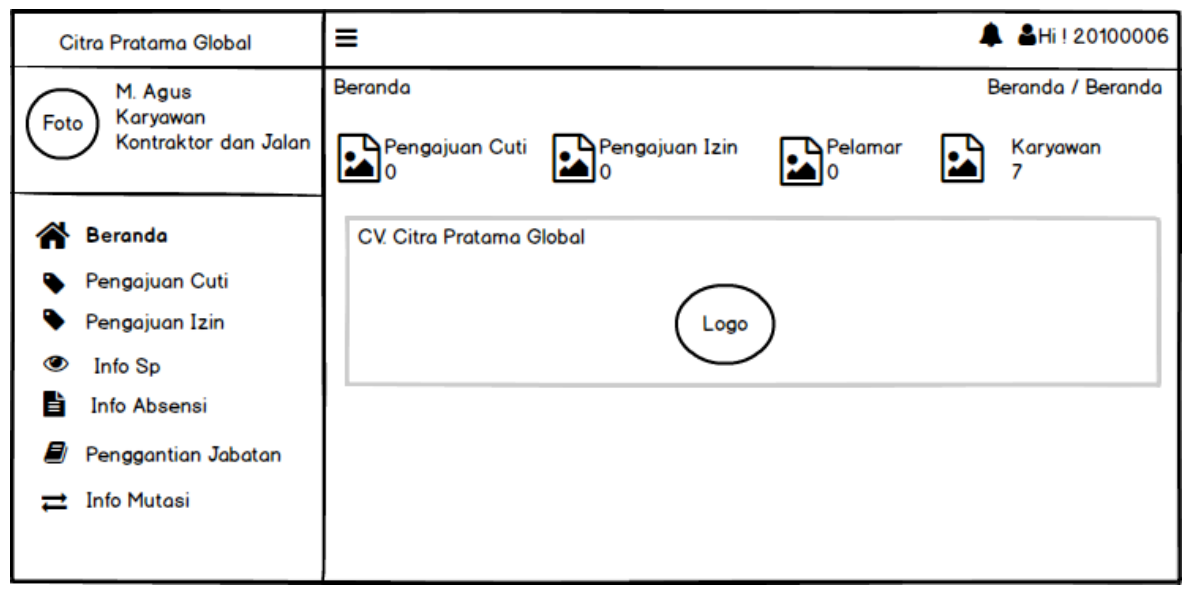

Gambar 7. Rancangan Antarmuka Beranda Karyawan

\subsection{Tampilan Antarmuka Sistem}

\subsubsection{Tampilan Antarmuka Beranda Pimpinan}

Tampilan antarmuka beranda pimpinan dapat dilihat pada Gambar 8. 


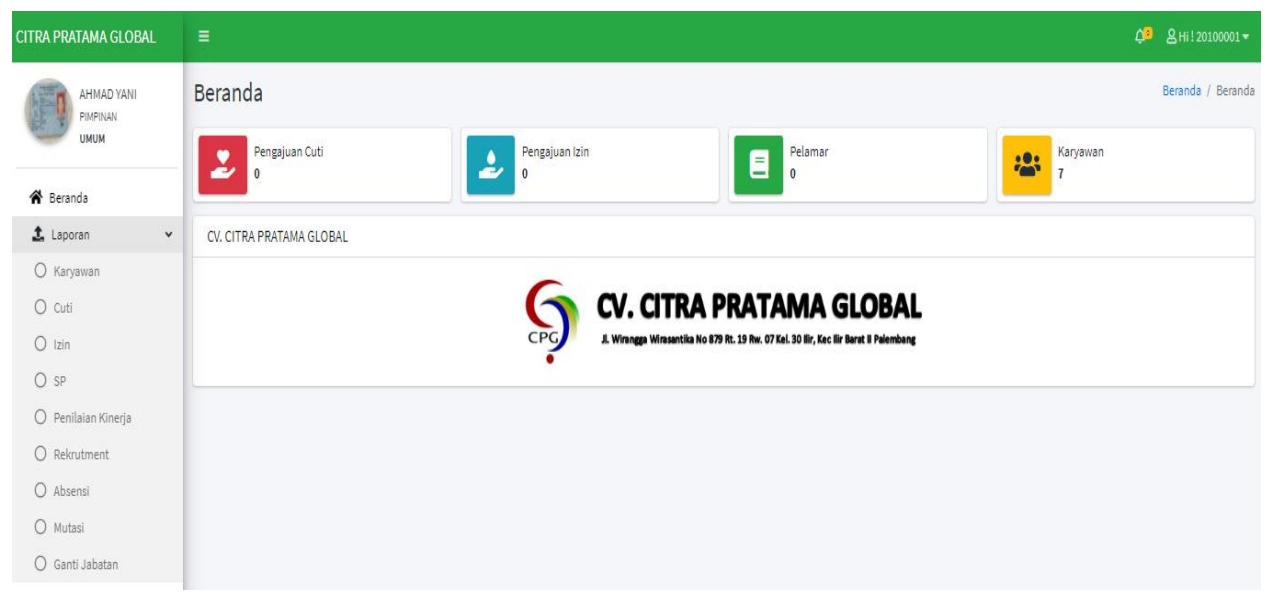

Gambar 8. Tampilan Antarmuka Beranda Pimpinan

\subsubsection{Tampilan Antarmuka Beranda HRD}

Tampilan antarmuka beranda HRD dapat dilihat pada Gambar 9

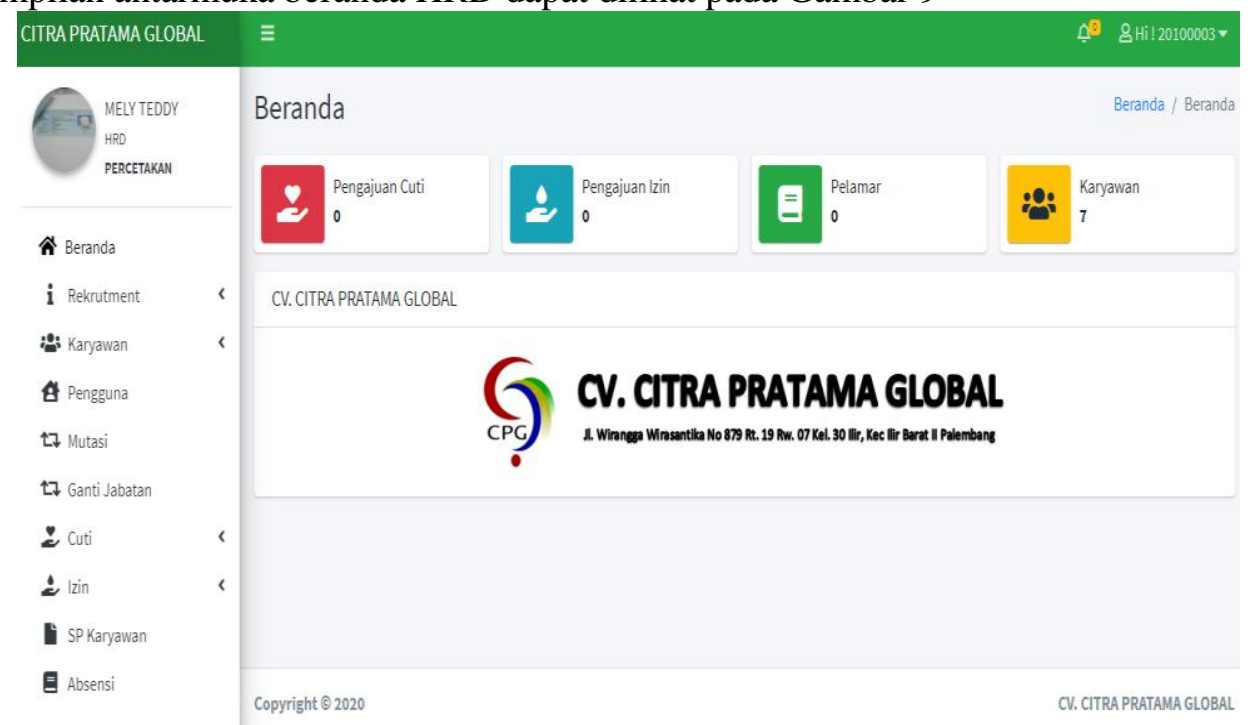

Gambar 9. Tampilan Antarmuka Beranda HRD

\subsubsection{Tampilan Antarmuka Beranda Supervisor}

Tampilan antarmuka beranda supervisor dapat dilihat pada gambar 10.

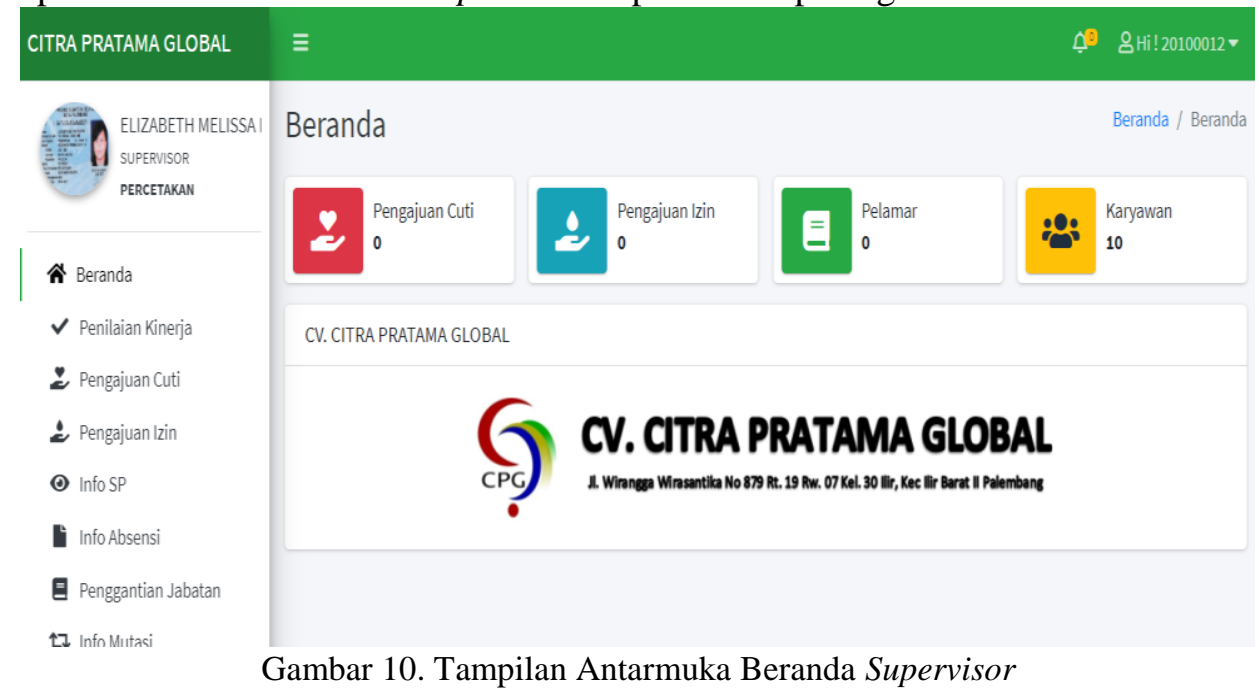




\subsubsection{Tampilan Antarmuka Beranda Karyawan}

Tampilan antarmuka beranda karyawan dapat dilihat pada Gambar 11.

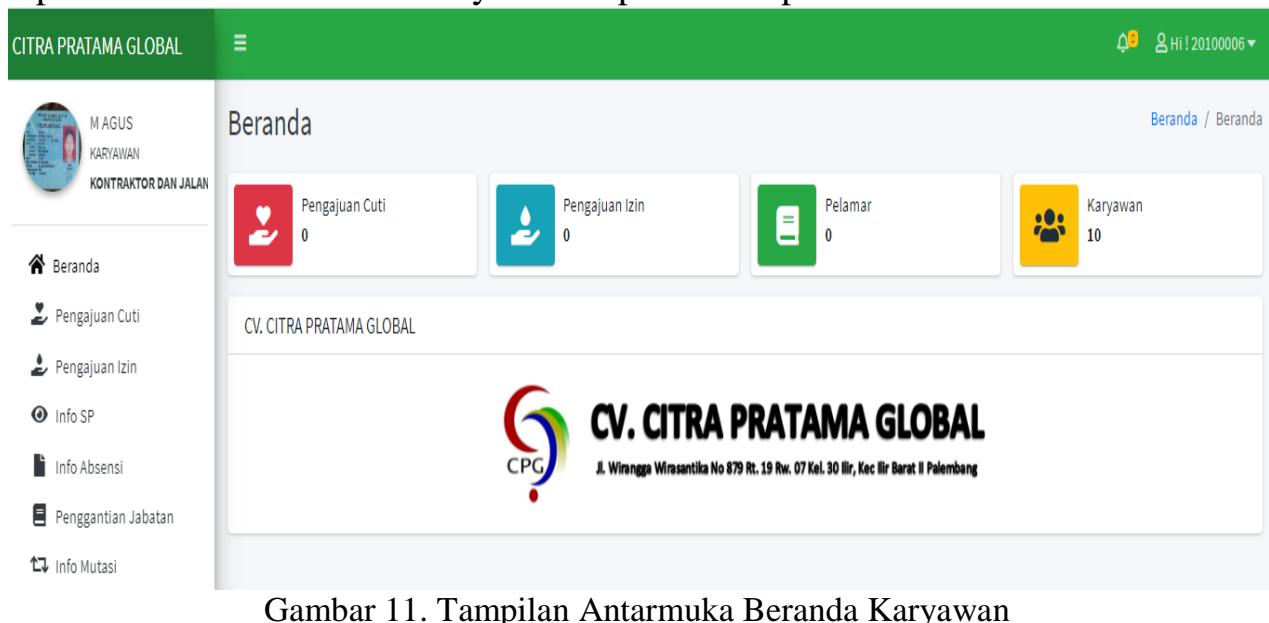

Gambar 11. Tampilan Antarmuka Beranda Karyawan

\section{KESIMPULAN}

Berdasarkan pengembangan sistem informasi kepegawaian berbasis web pada CV. Citra Pratama Global, penulis dapat mengambil kesimpulan sebagai berikut;

1. Sistem dapat mempermudah HRD dan Pimpinan untuk mendapatkan hasil laporan evaluasi kerja karyawan dengan lebih cepat dan akurat.

2. Dengan adanya fitur cuti dan izin dapat mengontrol perhitungan sisa jatah cuti sehingga karyawan tidak dapat mengajukan cuti kembali.

3. Sistem yang dirancang dapat membantu dalam rekapitulasi dan dokumentasi absensi sehingga dapat meminimalisir terjadinya manipulasi jam kerja.

4. Dengan adanya fitur rekrutmen dapat membantu mempermudah HRD dalam menyimpan record data calon karyawan sehingga proses seleksi rekrutmen lebih cepat.

\section{SARAN}

Penulis memberikan beberapa saran yang dapat diterapkan oleh CV. Citra Pratama Global, sebagai berikut;

1. Dalam penerapan sistem informasi kepegawaian ini diperlukan maintanace secara rutin agar sistem tetap dapat berfungsi dengan baik untuk memenuhi kebutuhan pengguna.

2. Disarankan melakukan backup pada data kepegawaian untuk mengantisipasi jika terjadi kerusakan dan kehilangan data.

3. Pada rekrutmen perlu ditambahkan rancangan seleksi penerimaan karyawan baru sehingga tidak hanya sebatas pada seleksi berkas lamaran.

4. Pada sistem informasi kepegawaian perlu ditambahkan fitur penggajian untuk bagian keuangan.

\section{DAFTAR PUSTAKA}

[1] Ramadhan Taopik, Rinda Cahyana, 2016, Pengembangan Sistem Informasi Kepegawaian pada Dinas Perindustrian Perdagangan dan Pengelolaan Pasar Kabupaten Garut, Jurnal STT-Garut. 
[2] Marimin, Hendri Tanjung, Haryo Prabowo 2006. Sistem Informasi Manajemen Sumber Daya Manusia. Grasindo, Bogor.

[3] Monica Lisa, Permata Sari, Intan. 2019. Sistem Informasi Kepegawaian Berbasis Desktop pada PT Indomarco Adi Prima Palembang.

[4] E. Kristinawati, 2014. Sistem Informasi Kepegawaian Berbasis Web Sebagai Pendukung Keputusan Pimpinan Di Stekom Semarang.

[5] Sukamto, Rosa A \& M Shalahuddin. 2013. Rekayasa Perangkat Lunak. Informatika, Bandung.

[6] Al-Fatta, Hanif. 2007. Analisis dan Perancangan Sistem Informasi. Andi Offset, Yogyakarta.

[7] Nur Laila, Wahyuni. 2011. Sistem Informasi Pengolahan Data Inventory pada Toko Buku Studi CV. Aneka Ilmu Semarang, Jurnal Unnes-Semarang.

[8] Sutanta, Edhy. 2011. Basis Data Dalam Tinjauan Konseptual. Andi Offset, Yogyakarta.

[9] E. Kendall, Kenneth 2010. Analisis dan Perancangan Sistem Jilid 1. PT Prenhallindo, Jakarta.

[10] A. Rossa and M. Salahuddin. 2013, Rekayasa Perangkat Lunak Terstruktur dan Berorientasi Objek. Informatika, Bandung. 